\title{
Laparoscopic versus open major liver resection for hepatocellular carcinoma: a case-matched analysis of short- and long-term outcomes
}

\author{
Aoxiao He \\ second affilated hospital of nanchang university \\ Yong Li \\ second affiliated hospital of nanchang university \\ Jiakun Wang \\ Peking University People's Hospital \\ Qian Feng \\ Nanchang Number 9 Hospital \\ Wenjun Liao \\ second affiliated hospital of nanchang university \\ Zhihao Huang \\ second affiliated hospital of nanchang university \\ Zhouqing Xiao \\ second affiliated hospital of nanchang university \\ Junjun Wu \\ second affiliated hospital of nanchang university \\ Long Peng \\ second affiliated hospital of nanchang university \\ linquan wu ( $\square$ Wulqnc@163.com) \\ second affiliated hospital of nanchang university
}

\section{Research}

Keywords: Lapaproscopic, open, hepatocellular carcinoma, case-matched analysis, live resection

Posted Date: April 7th, 2020

DOI: https://doi.org/10.21203/rs.3.rs-18533/v1

License: @ (i) This work is licensed under a Creative Commons Attribution 4.0 International License. Read Full License

Version of Record: A version of this preprint was published at Open Medicine on January 1st, 2021. See the published version at https://doi.org/10.1515/med2021-0308. 


\section{Abstract}

Background: The feasibility and safety of laparoscopic major hepatectomy $(\mathrm{LMH})$ is still uncertain. The purpose of the present study is to compare the shortand long-term outcomes of LMH with those of open major hepatectomy (OMH) for hepatocellular carcinoma (HCC).

Method: Between January 2012 and December 2018, a total of 26 patients received laparoscopic major hepatectomy in our center. To minimize any confounding factors, a 1:3 case-matched analysis was conducted based on the demographics and extent of liver resection. Data of demographics, perioperative outcomes and long-term oncologic outcomes were reviewed.

Results: Intraoperative blood loss $(P=0.007)$ were significantly lower in LMH group. In addition, LMH group exhibited a lower overall complication rate $(P=0.039)$ and shorter postoperative hospital stay $(P=0.024)$. However, no statistically significant difference was found between $\mathrm{LMH}$ and $\mathrm{OMH}$ regarding operation time $(P=0.215)$ and overall cost $(P=0.024)$. Two laparoscopic cases were converted to open liver resection. In regard with long-term outcomes, there was no significant difference between LMH and OMH regarding disease-free survival (DFS) $(P=0.079)$ and overall survival (OS) $(P=0.172)$.

Conclusion: $\mathrm{LMH}$ can be an effective and safe alternative to $\mathrm{OMH}$ for selected patients with liver cancer in short-and long-term outcomes.

\section{Introduction}

Laparoscopic liver resection (LLR) has been increasingly utilized by surgeons, since the first introduction of LLR in 1992 [1]. With the continuous development in laparoscopic devices and approaches, laparoscopic minor resections have even become standard surgical procedures for treating solitary lesion located in liver segments 2-6 [2-4]. However, laparoscopic major hepatectomy (LMH) has been relatively slow, because of LMH often correlated with a high risk of uncontrollable intraoperative bleeding, difficult procedures and high rate of conversion. The second International Consensus Conference of Morioka recommended that LMH comprised innovative procedures in the exploration phase and could only be performed in those with experience of major open liver resections and advanced laparoscopic techniques [4]. With accumulating the development of new instruments, the introduction of novel techniques, the improvements in surgical skills and experience of LLR, some recent studies reported that LMH and OMH had similar oncologic outcomes in patients with hepatocellular carcinoma (HCC) [5-8]. However, just a few studies described the long-term oncologic outcomes of LMH for HCC. Therefore, the present study aimed to compare the short- and long-term outcomes between LMH and OMH in patients with hepatic disease, especially those with HCC.

\section{Materials And Methods}

\section{Patients}

Between January 2012 and December 2018, we retrospectively collected data of 26 patients who underwent laparoscopic major hepatectomy (LMH) for hepatocellular carcinoma (HCC) at The Second Affiliated Hospital of Nanchang University. In addition, a 1:3 case-matched patients ( $\mathrm{n}=78$ ) who underwent open major hepatectomy $(\mathrm{OMH})$ was also collected based on the demographics and extent of liver resection. The study protocol was approved by the Institutional Review Board at the Second Affiliated Hospital of Nanchang University and the informed consents were taken from all patients. Data of the medical records including patient demographics, perioperative outcomes and long-term oncologic follow-up was retrieved. The patients were divided into two groups according to the type of procedure: LMH group $(n=26)$ and OMH group $(n=78)$. The study was conducted in accordance with the Helsinki Declaration of 1964 and all subsequent amendments, it was approved by the Ethics Committee of the Second Affiliated Hospital of Nanchang University in China, and all patients provided written informed consent.

\section{Definitions}

According to The Brisbane 2000 terminology, major hepatectomy $(\mathrm{MH})$ was defined as resection of more than 3 liver segments [9,10]. Because of right posterior sectionectomy and right anterior sectionectomy were difficult to perform by open laparoscopic hepatectomy, these procedures were also considered as major hepatectomy [11]. Overall complication was defined as those occurred within 30 days after hepatectomy. The Claviene-Dindo classification was used to grade the severity of complications [12]. Postoperative mortality was defined as those death within 90 days after surgery.

\section{Surgical procedures}

The preferred type of liver resection was anatomical resection, if indicated. The selection for type of liver resection was based on the remaining liver function, the proximity of lesion to major vascular structure, the number of lesions and the depth of the lesion. If the hepatic reserve was expected to be enough for the deep-seated lesion, major liver resection was performed. The hepatic reserve was evaluated in terms of the computed tomographic volumetry and indocyanine green retention rate at $15 \mathrm{~min}$ (ICG-R15). The indication of LMH was similar to that of OMH including the terms of the hepatic reserve, type of hepatectomy, and postoperative care $[13,14]$. For these patients with central lesions in the suprahepatic junction adjacent to the major hepatic vein and tumors adjacent or invading to the main portal pedicle or inferior vena cava, however, laparoscopic hepatectomy was not usually considered.

It has been described in more detail elsewhere for the techniques of $\mathrm{LMH}$ and $\mathrm{OMH}$ performed at our institution [13,14]. For both anatomical right or left hepatectomy, intraoperative ultrasonography was used routinely in order to decide the type of hepatectomy and get the free resection margin (Fig. 1A and B). The Glissonean approach was used to control the liver inflow before mobilization of the hepatic lobe (Fig. 1C and D). For right posterior sectionectomy or hemihepatectomy, multiple small hepatic veins were divided and the liver was fully mobilized from the inferior vena cava as much as possible. For left hemihepatectomy, the round ligament was firstly divided. Then, the left triangular ligaments and left falciform were dissected until the left hepatic vein was exposed. The left portal vein and hepatic artery were isolated and divided by Hem-o-lock clips and or Endo-GIA device, after fully mobilizing the left liver (Fig. $1 \mathrm{E}$ and $\mathrm{F}$ ). 
The same postoperative monitoring and care were used to all patients, which included routine liver function tests and blood examinations. The abdominal drainage was removed in the absence of bile leakage or peritonitis. Assessment of serum AFP levels, ultrasonography, CT and liver function tests were required bimonthly during the first postoperative year of follow-up. Then, the above tests should be required quarterly if no recurrence was detected. Recurrence was defined as HCC-characterisitc findings on follow up CT or MRI.

\section{Statistical analysis}

SPSS 17.0 software program (IMB Inc., Chicago, IL, USA) was used to process all data. Categorical variables were compared using $\chi^{2}$ test or Fisher's exact test as appropriate, and continuous parameters using Student's t test. Kaplan-Meier estimates for DFS and OS were compared between the LMH group and the $\mathrm{OMH}$ group using the log-rank test. $P<0.05$ was regarded as statistically significant.

\section{Results}

During the study period, a total of 456 consecutive patients were treated by hepatectomy. Of these patients, 26 patients underwent LMH, and a 1:3 casematched patients $(n=78)$ who underwent open major hepatectomy $(\mathrm{OMH})$ was also collected based on the demographics and extent of liver resection.

\section{Patients' characteristics}

Patients' characteristics of both groups were listed in Table 1. No significant differences were found between both groups in preoperative demographic characteristics, including gender, age, Child-Pugh classification, histologic cirrhosis, tumor size, and number of tumors.

\section{Surgical results}

The surgical results of both groups were listed in Table 2, and no mortality during surgery were observed. Two patients (7.7\%) in the laparoscopic group were converted to open procedure because of uncontrollable bleeding during parenchymal transection. A total 55 patients (70.5\%) were treated by portal triad clamping during hepatectomy in the $\mathrm{OMH}$ group, and 15 patients $(57.7 \%)$ was used in the $\mathrm{LMH}$ group $(P=0.227)$. Significantly less intraoperative blood loss was found in the LMH group than OMH group $(340.8 \pm 225.2 \mathrm{ml}$ vs. $601.4 \pm 509.4 \mathrm{ml}, P=0.007)$; however, no significant difference between LMH group and OMH group was found in intraoperative transfusion $(26.9 \%$ vs. $29.5 \%, P=0.803)$. In addition, the operation time did not differ significantly between both groups (264.2 $\pm 14.1 \mathrm{~min}$ vs. $255.4 \pm 36.3 \mathrm{~min}, P=0.215)$.

A total 18 patients (69.2\%) were performed by right hepatectomy in the LMH group and 54 patients (69.2\%) in the OMH. Pathologic examination of free resection margin was similar between both group $(96.2 \%$ vs. $91.0 \%, P=0.671)$.

\section{Postoperative outcomes and cost}

Postoperative results of both groups were listed in Table 2 . There were one laparoscopy patient (3.8\%) and five (6.4\%) patients undergoing open surgery with hepatectomy related complications after surgery $(P=1.000)$. Overall complications were significantly lower in the LMH group comparing with OMH group (15.4\% vs. $37.2 \%, P=0.039)$. There was no perioperative mortality between both groups. Although no significant difference was found in recovery of bowel movement ( $1.5 \pm 0.5$ days vs. $3.1 \pm 0.6$ days, $P=0.083)$ between both groups, the time of off-bed activities $(2.8 \pm 0.6$ days vs. $4.9 \pm 1.1$ days, $P=0.003)$ and postoperative hospital stay ( $11.0 \pm 2.9$ days vs. $15.5 \pm 5.2$ days, $P=0.024)$ were significantly shorter in $\mathrm{LMH}$ group comparing with $0 \mathrm{MH}$ group. Both the surgical and overall costs were collected. Interesting, we found that although no significant difference was found in surgical cost between both groups (4850.0 $\pm 1041.8 \mathrm{RMB}$ vs. $4790.3 \pm 904.3 \mathrm{RMB}, P=0.860$ ), the overall cost of $\mathrm{LMH}$ group was significantly lower than $\mathrm{OMH}$ group (56306.4 $\pm 9477.5 \mathrm{RMB}$ vs. $59251.9 \pm 16075.6 \mathrm{RMB}, P=0.024)$.

\section{Long-term survival outcomes}

The median follow-up was (33.3 \pm 15.6$)$ months in the LMH group and (31.4 \pm 15.7$)$ months in the OLH group, and no significant difference was found between both groups ( $P=0.752$ ). Median DFS of LMH and OMH groups was 63.0 months [95\% confidence interval (Cl) $31.8-94.1$ months] and 36.0 months ( $95 \% \mathrm{Cl}$ 29.7-42.3 months), respectively (Fig. 2A). Median OS of LMH and OMH groups was 60.0 months (95\% Cl 50.3-69.7 months) and 60.0 months (95\% Cl 47.6 72.4 months) (Fig. 2B). No significant difference in DFS $(P=0.079)$ and $O S(P=0.172)$ was found between both groups.

\section{Discussion}

With the continuous development in laparoscopic devices and approaches, laparoscopic minor liver resections have even become standard surgical procedures for treating solitary lesion located in liver segments 2-6 [2-4]. Due to the long learning curve for laparoscopic liver resection, it is necessity to consider the expertise of the surgeon for safe laparoscopic minor resection $[15,16]$. Recently, in some highly specialized centers, LMH can be performed as effectively and safely as $\mathrm{OMH}$ [3]. $\mathrm{LMH}$ even was not inferior to $\mathrm{OMH}$ in terms of resection margin, postoperative complications, operative mortality and longterm outcomes stated by the Second International Consensus Conference held in Morioka; in addition, LLR was superior in terms of shorter hospital stay [4].

As showed in table 3, we have summarized all comparative studies of major LLR vs. major OLR [4-8,17-23]. The negative margins and oncologic integrity of the procedure should be obtained, when major laparoscopic liver resection is performed for cancer. No difference in the resection margin was found in the comparative studies of major LLR vs. major OLR, although tumor size of major LLR was large than major OLR in the studies of Goumard [8], Guro [17], Komatsu [18] and Tarantino [20]. In the present case-matched study, the negative margin of major LLR was similar to major OLR. In addition, the RO resection 
rate of LMH group was $96.2 \%$. Recently, some meta-analyses of retrospective studies also observed that no significant difference was found between major LLR and major OLR in the resection margin for HCC patients $[24,25]$. In order to better learn major LLR for HCC patients, long-term survival rate should also be obtained. As showed in table 3, there were three studies provided data of five-year over survival (OS) and disease-free survival (DFS) including the data of our study. Although laparoscopic group has a longer OS comparing with open group, no significant difference was found between both groups in regarding with OS and DFS. Therefore, we can conclude that major LLR may be as oncological safety as major OLR. Due to the above data come from observational clinical studies (OCS), however, additional randomized controlled trials (RCTs) studies are required to provide convincing evidence in the future.

With regard to the data on perioperative outcomes, major LLR was associated with favorable intraoperative blood loss, total postoperative complications and postoperative hospital stay in the summarized comparative studies. However, the operation time of major LLR was significantly longer than major OLR in most of the retrospective studies [4-8,17-19,21,22]. Recently, the Japanese National Clinical Database showed that major LLR was associated with less blood loss, a lower complication rate and shorter hospital stay comparing with major OLR [26]. Regarding short-term outcomes in the present study, the average operation time of major LLR group was longer than OLR group. However, major LLR group has a significantly lower intraoperative blood loss and postoperative complication rate and shorter postoperative hospital stay. This indicates that although major LLR is technically more difficult than OLR, major LLR is similar to major OLR in short-term outcomes. Furthermore, owing to its minimal invasiveness, major LLR facilitates earlier patient recovery. Interesting, our results showed that although no significant difference was found in surgical cost between both groups, the overall cost of LMH group was significantly lower than $\mathrm{OMH}$ group which might be related with fast recovering.

To the best of our knowledge, the present report was the first study summarized the long-term survival rate of major LLR in patients with HCC. However, several limitations should be care in our study. First, this was a retrospective study, which may introduce bias. Second, although there was no difference in the resection margin between the two groups, we preferred major OLR in patients with HCC close to the major Glisson pedicle or the inferior vena cava. In conclusion, major LLR of HCC is feasible and safe with favorable short- and long-term outcomes, when performed in experienced centers.

\section{Declarations}

\section{Acknowledgments}

Not applicable

\section{Funding}

The present study was supported by grants from the Department of Education Project of Jiangxi Province,China(Grant No. GJJ180079 and No. CJJ180083),the Key Research and Development Project of Science and Technology Department of Jiangxi

Province,China.(Grant No. 20181BBG70025).

\section{Availability of data and materials}

The data sets used or analyzed in this study are available from the corresponding author on reasonable request.All patients provided written informed consent.

\section{Authors'contributions}

Aoxiao He,Yong Li,Long Peng and Linquan Wu conceived and designed the study; collected, assembled, analyzed, and interpreted the data; wrote the manuscript; and approved the final manuscript.Jiakun Wang,Qian Feng and Wenjun Liao collected, assembled, analyzed, and interpreted the data; wrote the manuscript; and approved the final manuscript.Zhihao Huang,Zhouqing Xiao and Junjun WU conceived and designed the study, helped perform the analysis with constructive discussions, and approved the final manuscript.

\section{Ethics approval and consent to participate}

The study was conducted in accordance with the Helsinki Declaration of 1964 and all subsequent amendments, it was approved by the Ethics Committee of the Second Affiliated Hospital of Nanchang University in China.

\section{Consent for publication}

Not applicable.

\section{Competing interests}

The authors declare that they have no competing interests.

\section{References}

1. Gagner M, Rheault M, Dubuc J (1992) Laparoscopic partial hepatectomy for liver tumor. Surg Endosc 6:97-98.

2. Lee GC, Kwon CHD, Joh JW et al (2011) Preliminary experience of laparoscopic hepatectomy for hepatocellular carcinoma. Korean J Hepatobiliary Pancreat Surg 15:7-12

3. Buell JF, Cherqui D, Geller DA et al (2009) The international position on laparoscopic liver surgery: the Louisville Statement, 2008. Ann Surg 250:825-830 
4. Wakabayashi G, Cherqui D, Geller DA et al (2015) Recommendations for laparoscopic liver resection: a report from the second international consensus conference held in Morioka. Ann Surg 261:619-629

5. Chen J, Li H, Liu F, et al. Surgical outcomes of laparoscopic versus open liver resection for hepatocellular carcinoma for various resection extent. Medicine. 2017;96:e6460.

6. Cho C W, Rhu J, Kwon C H D, et al. Short-Term Outcomes of Totally Laparoscopic Central Hepatectomy and Right Anterior Sectionectomy for Centrally Located Tumors: A Case-Matched Study with Propensity Score Matching[J]. World Journal of Surgery, 2017.

7. Cho JY, Han HS, Yoon YS, et al. Outcomes of laparoscopic right posterior sectionectomy in patients with hepatocellular carcinoma in the era of laparoscopic surgery. Surgery. 2015;158: 135-141.

8. Guro H, Cho J Y , Han H S , et al. Outcomes of major laparoscopic liver resection for hepatocellular carcinoma[J]. Surgical Oncology, 2018, 27(1):31-35.

9. Reddy SK, Barbas AS, Turley RS, et al. A standard definition of major hepatectomy: resection of four or more liver segments. HPB. 2011 Jul 1;13(7): 494e502.

10. M. Strasberg, Nomenclature of hepatic anatomy and resections: a review of the Brisbane 2000 system, J. Hepatobiliary Pancreat. Surg. 12 (2005) $351 \mathrm{e} 355$

11. Lee MKt, F. Gao, S.M. Strasberg, Completion of a liver surgery complexity score and classification based on an international survey of experts, J. Am. Coll. Surg. 223 (2016) 332e342.

12. Dindo, N. Demartines, P.A. Clavien, Classification of surgical complications: a new proposal with evaluation in a cohort of 6336 patients and results of a survey, Ann. Surg. 240 (2004) 205e213.

13. Zhou F, Shao J H, Zou S B, et al. Laparoscopic hepatectomy is associated with a higher incident frequency in hepatolithiasis patients. Surgery Today, 2013, 43(12):1371-1381.

14. Peng L, Xiao J, Liu Z, et al. Laparoscopic left-sided hepatectomy for the treatment of hepatolithiasis: A comparative study with open approach. International Journal of Surgery, 2017, 40(Complete):117-123.

15. Dagher, G. Belli, C. Fantini, A. Laurent, C. Tayar, P. Lainas, H. Tranchart, D. Franco, D. Cherqui, Laparoscopic hepatectomy for hepatocellular carcinoma: a European experience, J. Am. Coll. Surg. 211 (2010) $16 \mathrm{e} 23$.

16. C. Martin, C.R. Scoggins, K.M. McMasters, Laparoscopic hepatic lobectomy: advantages of a minimally invasive approach, J. Am. Coll. Surg. 210 (627e634) (2010), 634e626.

17. Goumard C, Komatsu S, Brustia R, et al. Technical feasibility and safety of laparoscopic right hepatectomy for hepatocellular carcinoma following sequential TACE-PVE: a comparative study. Surgical Endoscopy, 2017, 31(5):2340-2349.

18. Komatsu S, Brustia R, Goumard C, et al. Laparoscopic versus open major hepatectomy for hepatocellular carcinoma: a matched pair analysis. Surg Endosc. 2016;30:1965-1974.

19. Rhu J, Kim SJ, Choi GS, et al. Laparoscopic versus open right posterior sectionectomy for hepatocellular carcinoma in a highvolume center: a propensity score matched analysis. World J Surg. 2018; 42:2930-2937.

20. Tarantino G, Magistri P, Serra V, et al. Laparoscopic liver resection of right posterior segments for hepatocellular carcinoma on cirrhosis. $J$ Laparoendosc Adv Surg Tech A. 2017;27:559-563.

21. Yoon YI, Kim KH, Kang SH, et al. Pure laparoscopic versus open right hepatectomy for hepatocellular carcinoma in patients with cirrhosis: a propensity score matched analysis. Ann Surg. 2017;265:856-863.

22. Zhang Y, Chen XM, Sun DL. Short-term Outcomes of Laparoscopic Versus Open Right Hemihepatectomy for Hepatocellular Carcinoma. Surg Laparosc Endosc Percutan Tech. 2016;26:e157-e160.

23. Zhang Y, Huang J, ChenXM, et al. A comparison of laparoscopic versus open left hemihepatectomy for hepatocellular carcinoma. Surg Laparosc Endosc Percutan Tech. 2016;26:146-149.

24. Kasai M, Cipriani F, Gayet B, et al. Laparoscopic versus open major hepatectomy: a systematic review and meta-analysis of individual patient data. Surgery, 2018:S0039606018300394.

25. Xu H, Liu F, Li H, et al. Outcomes following laparoscopic versus open major hepatectomy: a meta-analysis. Scandinavian Journal of Gastroenterology, 2017:1-8.

26. Takahara, G. Wakabayashi, H. Konno, M. Gotoh, H. Yamaue, K. Yanaga, J. Fujimoto, H. Kaneko, M. Unno, I. Endo, Y. Seto, H. Miyata, M. Miyazaki, M. Yamamoto, Comparison of laparoscopic major hepatectomy with propensity score matched open cases from the National Clinical Database in Japan, J. Hepatobiliary Pancreat. Sci. 2016;23:721e734.

\section{Tables}


Table 1 patients' characteristics and perioperative outcomes

\begin{tabular}{|c|c|c|c|}
\hline & LMH $(n=26)$ & $\mathrm{OMH}(\mathrm{n}=78)$ & $p$ value \\
\hline Gender (M:F) & $11: 15$ & $33: 45$ & 1.000 \\
\hline Age (years) & $56.1 \pm 10.6$ & $52.0 \pm 12.2$ & 0.698 \\
\hline \multicolumn{4}{|l|}{ Child-Pugh class, no. ( $\square)$} \\
\hline A & $23(88.5 \%)$ & $70(89.7 \%)$ & 1.000 \\
\hline B & $3(11.5 \%)$ & $8(10.3 \%)$ & \\
\hline Histologic cirrhosis, no. ( $\square)$ & $16(61.5 \%)$ & $45(57.7 \%)$ & 0.730 \\
\hline Tumor size (mm) & $75.0 \pm 35.1$ & $75.5 \pm 38.8$ & 0.378 \\
\hline Number of tumors & $1.3 \pm 0.6$ & $1.4 \pm 0.7$ & 0.381 \\
\hline
\end{tabular}

LMH laparoscopic major hepatectomy, OMH open major hepatectomy, M male, F female.

Table 2 Operative outcomes

\begin{tabular}{|c|c|c|c|}
\hline & $\mathrm{LMH}(\mathrm{n}=26)$ & $\mathrm{OMH}(\mathrm{n}=78)$ & $P$ value \\
\hline Operation time (min) & $264.2 \pm 14.1$ & $255.4 \pm 36.3$ & 0.215 \\
\hline Intraoperative blood loss (ml) & $340.8 \pm 225.2$ & $601.4 \pm 509.4$ & 0.007 \\
\hline Intraoperative transfusion no. ( $\square$ ) & $7(26.9 \%)$ & $23(29.5 \%)$ & 0.803 \\
\hline Total complication, no. ( $\square)$ & $4(15.4 \%)$ & $29(37.2 \%)$ & 0.039 \\
\hline Wound infection & $2(7.7 \%)$ & $6(7.7 \%)$ & 1.000 \\
\hline Bile leakage & $1(3.8 \%)$ & $5(6.4 \%)$ & 1.000 \\
\hline Intraabdominal fluid collection & $1(3.8 \%)$ & $10(12.8 \%)$ & 0.357 \\
\hline Bleeding & 0 & $1(1.3 \%)$ & 1.000 \\
\hline Pulmonary infection & 0 & $5(6.4 \%)$ & 0.427 \\
\hline Abdominal incisional hernia & 0 & $2(2.6 \%)$ & 1.000 \\
\hline Recovery of bowel movement, days & $1.5 \pm 0.5$ & $3.1 \pm 0.6$ & 0.083 \\
\hline Time of off-bed activities, days & $2.8 \pm 0.6$ & $4.9 \pm 1.1$ & 0.003 \\
\hline Postoperative hospital stay, days & $11.0 \pm 2.9$ & $15.5 \pm 5.2$ & 0.024 \\
\hline pR1, no. (\%) & $1(3.8 \%)$ & $7(9.0 \%)$ & 0.671 \\
\hline $\mathrm{pRM}(\mathrm{mm})$ & $7.5 \pm 35.1$ & $7.1 \pm 36.4$ & 0.895 \\
\hline Operative cost (RMB) & $4850.0 \pm 1041.8$ & $4790.3 \pm 904.3$ & 0.860 \\
\hline Overall cost (RMB) & $56306.4 \pm 9477.5$ & $59251.9 \pm 16075.6$ & 0.024 \\
\hline
\end{tabular}

LMH laparoscopic major hepatectomy, OMH open major hepatectomy, pR1 positive surgical resection margin, pRM pathological resection margin. 
Table 3 Main characteristics of the comparative studies of of major LLR vs. major OLR.

\begin{tabular}{|c|c|c|c|c|c|c|c|c|c|c|c|}
\hline Authors & $\begin{array}{l}\text { Type of } \\
\text { Surgery }\end{array}$ & $\begin{array}{l}\text { No. of } \\
\text { patients }\end{array}$ & $\begin{array}{l}\text { Tumor } \\
\text { size } \\
(\mathrm{mm})\end{array}$ & $\begin{array}{l}\text { Number } \\
\text { of } \\
\text { tumors }\end{array}$ & $\begin{array}{l}\text { Resection } \\
\text { margins } \\
(\mathrm{mm})\end{array}$ & $\begin{array}{l}\text { Operation } \\
\text { time } \\
\text { (min) }\end{array}$ & $\begin{array}{l}\text { Intraoperative } \\
\text { blood loss } \\
\text { (mL) }\end{array}$ & $\begin{array}{l}\text { No. } \\
\text { transfusions }\end{array}$ & $\begin{array}{l}\text { Total } \\
\text { complications }\end{array}$ & $\begin{array}{l}\text { Postoperative } \\
\text { hospital stay } \\
\text { (days) }\end{array}$ & \\
\hline \multirow[t]{2}{*}{$\begin{array}{l}\text { Chen et } \\
\text { al [5] }\end{array}$} & LMH & 126 & 64 & $112 / 14$ & NA & $\begin{array}{l}240(75- \\
590)\end{array}$ & $200(20-2500)$ & $6(4.8 \%)$ & $28(22.2 \%)$ & $6(3-21)$ & \\
\hline & $\mathrm{OMH}$ & 133 & $\begin{array}{l}130) \\
(16- \\
240)\end{array}$ & $110 / 23$ & NA & $\begin{array}{l}230(100- \\
495)\end{array}$ & $400(50-2000)$ & $22(16.5 \%)$ & 36 (27.1\%) & $8(4-46)$ & \\
\hline \multirow[t]{2}{*}{$\begin{array}{l}\text { Cho et al } \\
{[6]}\end{array}$} & LRPS & 24 & $\begin{array}{l}37 \pm \\
18\end{array}$ & NA & $3.0 \pm 5.8$ & $\begin{array}{l}567.4 \pm \\
212.4\end{array}$ & NA & NA & $2(8.3 \%)$ & $10.6 \pm 4.8$ & \\
\hline & ORPS & 19 & $\begin{array}{l}48 \pm \\
25\end{array}$ & NA & $7.0 \pm 5.0$ & $\begin{array}{l}316.1 \pm \\
63.0\end{array}$ & NA & NA & $4(21.1 \%)$ & $11.1 \pm 3.2$ & \\
\hline \multirow{2}{*}{$\begin{array}{l}\text { Cho et al } \\
{[7]}\end{array}$} & $\mathrm{LCH}$ & 20 & $\begin{array}{l}26(6- \\
140)\end{array}$ & NA & $\begin{array}{l}7(0.1- \\
40)\end{array}$ & $\begin{array}{l}388 \text { (246- } \\
661)\end{array}$ & $\begin{array}{l}350(100- \\
1300)\end{array}$ & $2(10 \%)$ & $6(30 \%)$ & $8(5-24)$ & \\
\hline & $\mathrm{OCH}$ & 20 & $\begin{array}{l}27 \\
(10- \\
82)\end{array}$ & NA & $\begin{array}{l}6.5 \\
23)\end{array}$ & $\begin{array}{l}268(98- \\
412)\end{array}$ & $400(50-3300)$ & $1(5 \%)$ & $4(20 \%)$ & $10(5-24)$ & \\
\hline \multirow[t]{2}{*}{$\begin{array}{l}\text { Goumard } \\
\text { et al [8] }\end{array}$} & LRH & 16 & $\begin{array}{l}39(2- \\
85)\end{array}$ & $\begin{array}{l}1.5(1- \\
3)\end{array}$ & $\begin{array}{l}13.5(0- \\
50)\end{array}$ & $\begin{array}{l}360(240- \\
450)\end{array}$ & $150(100-700)$ & $1(6.3 \%)$ & $4(25 \%)$ & $7(5-11)$ & ( \\
\hline & $\mathrm{ORH}$ & 16 & $\begin{array}{l}62(0- \\
250)\end{array}$ & $\begin{array}{l}1.5(1- \\
3)\end{array}$ & $\begin{array}{l}6.5(0- \\
60)\end{array}$ & $\begin{array}{l}300(240- \\
390)\end{array}$ & $100(100-800)$ & $0(0 \%)$ & $8(50 \%)$ & $12(7-25)$ & \\
\hline \multirow[t]{2}{*}{$\begin{array}{l}\text { Guro et } \\
\text { al [17] }\end{array}$} & LMH & 67 & $\begin{array}{l}41 \pm \\
24\end{array}$ & NA & $2(2.4 \%)$ & $\begin{array}{l}416.6 \pm \\
166.9\end{array}$ & $\begin{array}{l}1543.3 \pm \\
2641.8\end{array}$ & $29(34.9 \%)$ & $17(20.5 \%)$ & $11.3 \pm 8.3$ & \\
\hline & $\mathrm{OMH}$ & 110 & $\begin{array}{l}63 \pm \\
38\end{array}$ & NA & $6(5.4 \%)$ & $\begin{array}{l}332.5 \pm \\
105.4\end{array}$ & $\begin{array}{l}1248.1 \pm \\
1402.8\end{array}$ & $45(40.5 \%)$ & 43 (38.7\%) & $18 \pm 21.4$ & \\
\hline \multirow[t]{2}{*}{$\begin{array}{l}\text { Komatsu } \\
\text { et al [18] }\end{array}$} & LMH & 38 & $\begin{array}{l}47.5 \\
(23- \\
180)\end{array}$ & $19 / 19$ & $\begin{array}{l}6 \\
(15.8 \%)\end{array}$ & $\begin{array}{l}365(180- \\
600)\end{array}$ & $100(20-900)$ & $2(5.2 \%)$ & $12(31.6 \%)$ & $7.5(3-51)$ & \\
\hline & $\mathrm{OMH}$ & 38 & $\begin{array}{l}85.0 \\
(20- \\
180)\end{array}$ & $16 / 22$ & $\begin{array}{l}6 \\
(15.8 \%)\end{array}$ & $\begin{array}{l}300(210- \\
425)\end{array}$ & $80(20-800)$ & $1(2.6 \%)$ & 23 (60.5\%) & $10.0(5-53)$ & ] \\
\hline \multirow[t]{2}{*}{$\begin{array}{l}\text { Rhu et al } \\
\text { [19] }\end{array}$} & LRPS & 53 & $\begin{array}{l}31 \pm \\
18\end{array}$ & $47 / 6$ & $13 \pm 10$ & $381 \pm 149$ & NA & $7(13.2)$ & $5(9.4 \%)$ & $8.9 \pm 3.6$ & \\
\hline & ORPS & 97 & $\begin{array}{l}31 \pm \\
17\end{array}$ & $89 / 8$ & $12 \pm 9$ & $220 \pm 91$ & NA & $2(2.1)$ & $8(8.3 \%)$ & $10.2 \pm 3.6$ & \\
\hline \multirow[t]{2}{*}{$\begin{array}{l}\text { Tarantino } \\
\text { et al [20] }\end{array}$} & LRPS & 13 & $27 \pm 9$ & $\begin{array}{l}1.0 \pm \\
0.2\end{array}$ & $10 \pm 3$ & $234 \pm 57$ & $125 \pm 80$ & NA & $2(15.3 \%)$ & $5.7 \pm 3$ & ] \\
\hline & ORPS & 51 & $\begin{array}{l}37 \pm \\
23\end{array}$ & $\begin{array}{l}1.0 \pm \\
0.2\end{array}$ & $10 \pm 2$ & $216 \pm 73$ & $208 \pm 263$ & NA & 27 (52.9\%) & $10.7 \pm 5$ & ] \\
\hline \multirow[t]{2}{*}{$\begin{array}{l}\text { Yoon et } \\
\text { al [21] }\end{array}$} & LRH & 33 & $\begin{array}{l}33.1 \\
\pm 16.5\end{array}$ & $\begin{array}{l}1.1 \\
\pm 0.2\end{array}$ & $26 \pm 21$ & $297 \pm 113$ & $125.5 \pm 229$ & $0(0)$ & $1(3.03 \%)$ & $9.97 \pm 3.02$ & ] \\
\hline & $\mathrm{ORH}$ & 33 & $\begin{array}{l}29.6 \\
\pm 15\end{array}$ & $\begin{array}{l}1.1 \\
\pm 0.2\end{array}$ & $20 \pm 15$ & $176 \pm 60$ & $132 \pm 178$ & $0(0)$ & 7 (21.21\%) & $13.94 \pm 3.37$ & ] \\
\hline $\begin{array}{l}\text { Zhang et } \\
\text { al [22] }\end{array}$ & LRH & 35 & $67 \pm 42$ & NA & $35 / 0$ & $309 \pm 108$ & $293 \pm 82.5$ & NA & 0 & $9 \pm 2$ & \\
\hline $\begin{array}{l}\text { Zhang et } \\
\text { al [23] }\end{array}$ & $\begin{array}{l}\text { ORH } \\
\text { LLH }\end{array}$ & $\begin{array}{l}42 \\
20\end{array}$ & $\begin{array}{l}59 \pm 30 \\
67 \pm 42\end{array}$ & $\begin{array}{l}\text { NA } \\
\text { NA }\end{array}$ & $\begin{array}{l}42 / 0 \\
20 / 0\end{array}$ & $\begin{array}{l}223 \pm 110 \\
143 \pm 35.6\end{array}$ & $\begin{array}{l}433 \pm 105.5 \\
180 \pm 20.5\end{array}$ & $\begin{array}{l}\text { NA } \\
\text { NA }\end{array}$ & $\begin{array}{l}21(50 \%) \\
0\end{array}$ & $\begin{array}{l}15 \pm 3 \\
7 \pm 1\end{array}$ & $\begin{array}{l}\text { ] } \\
]\end{array}$ \\
\hline \multirow[t]{2}{*}{$\begin{array}{l}\text { Our } \\
\text { results }\end{array}$} & $\begin{array}{l}\text { OLH } \\
\text { LMH }\end{array}$ & $\begin{array}{l}25 \\
26\end{array}$ & $\begin{array}{l}59 \pm 30 \\
75 \pm 35\end{array}$ & $\begin{array}{l}\mathrm{NA} \\
1.3 \pm 0.6\end{array}$ & $\begin{array}{l}25 / 0 \\
7.5 \pm \\
35.1\end{array}$ & $\begin{array}{l}137 \pm 29.8 \\
264.2 \pm 14.1\end{array}$ & $\begin{array}{l}350 \pm 45.3 \\
340.8 \pm 225.2\end{array}$ & $\begin{array}{l}\text { NA } \\
7(26.9 \%)\end{array}$ & $\begin{array}{l}10(40 \%) \\
4(15.4 \%)\end{array}$ & $\begin{array}{l}12 \pm 2 \\
11.0 \pm 2.9\end{array}$ & $\begin{array}{l}1 \\
1\end{array}$ \\
\hline & $\mathrm{OMH}$ & 78 & $76 \pm 39$ & $1.4 \pm 0.7$ & $\begin{array}{l}7.1 \pm \\
36.4 \\
\end{array}$ & $255.4 \pm 36.3$ & $601.4 \pm 509.4$ & 23 (29.5\%) & 29 (37.2\%) & $15.5 \pm 5.2$ & \\
\hline
\end{tabular}

LCH, laparoscopic central hepatectomy; LRPS, laparoscopic right posterior sectionectomy; LRH, laparoscopic right hepatectomy; LLH, 1 hemihepatectomy

Statistically significant results are shown in bold.

\section{Figures}



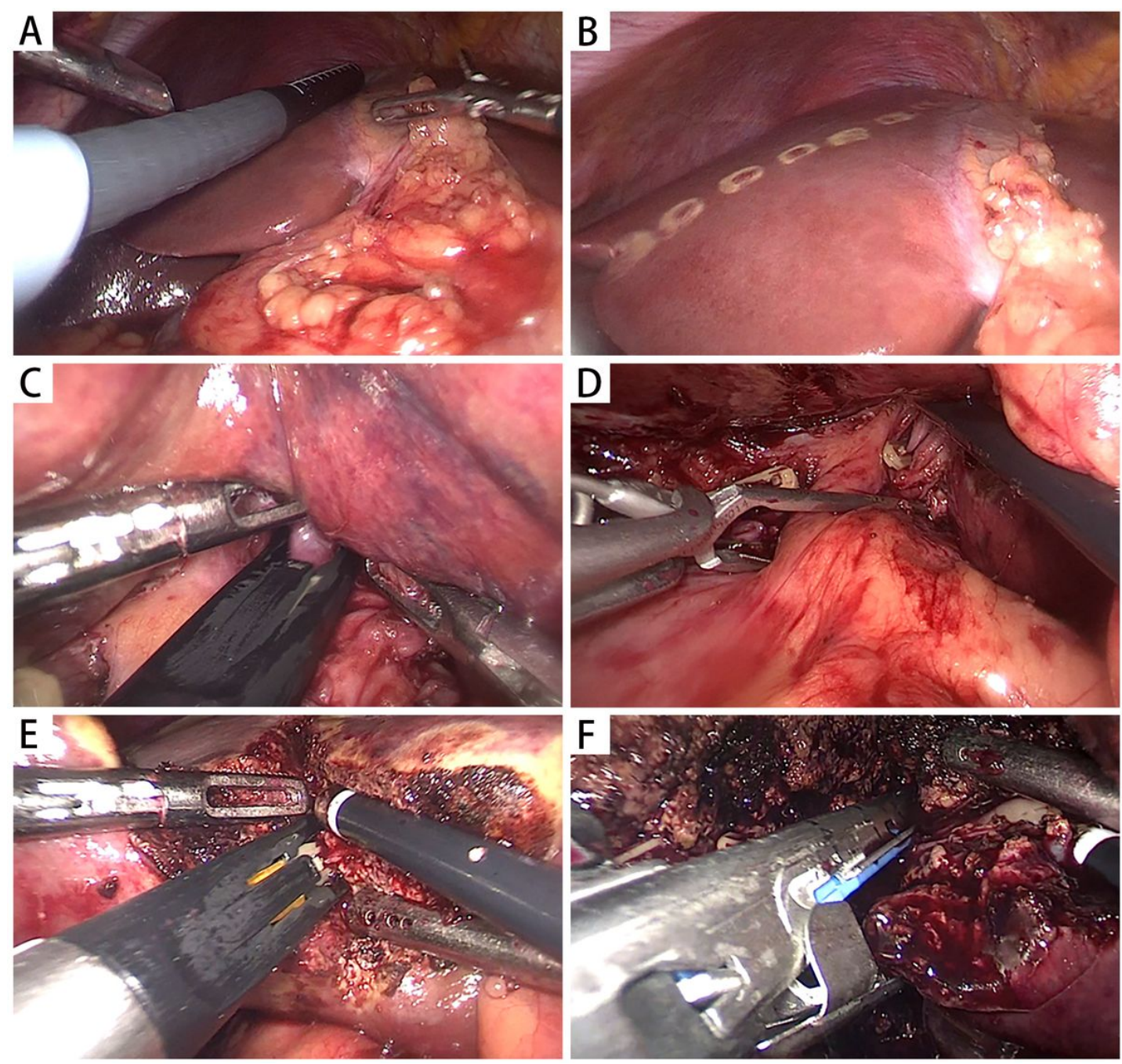

\section{Figure 1}

Surgical techniques for $\mathrm{LMH}$. (A) and (B) intraoperative ultrasonography is used routinely and the hepatic transection line was marked. (C) and (D) The Glissonean approach is used to control the liver inflow. $(E)$ and $(F)$ The left portal vein and hepatic artery are isolated and divided by Hem-o-lock clips and/or Endo-GIA device. 

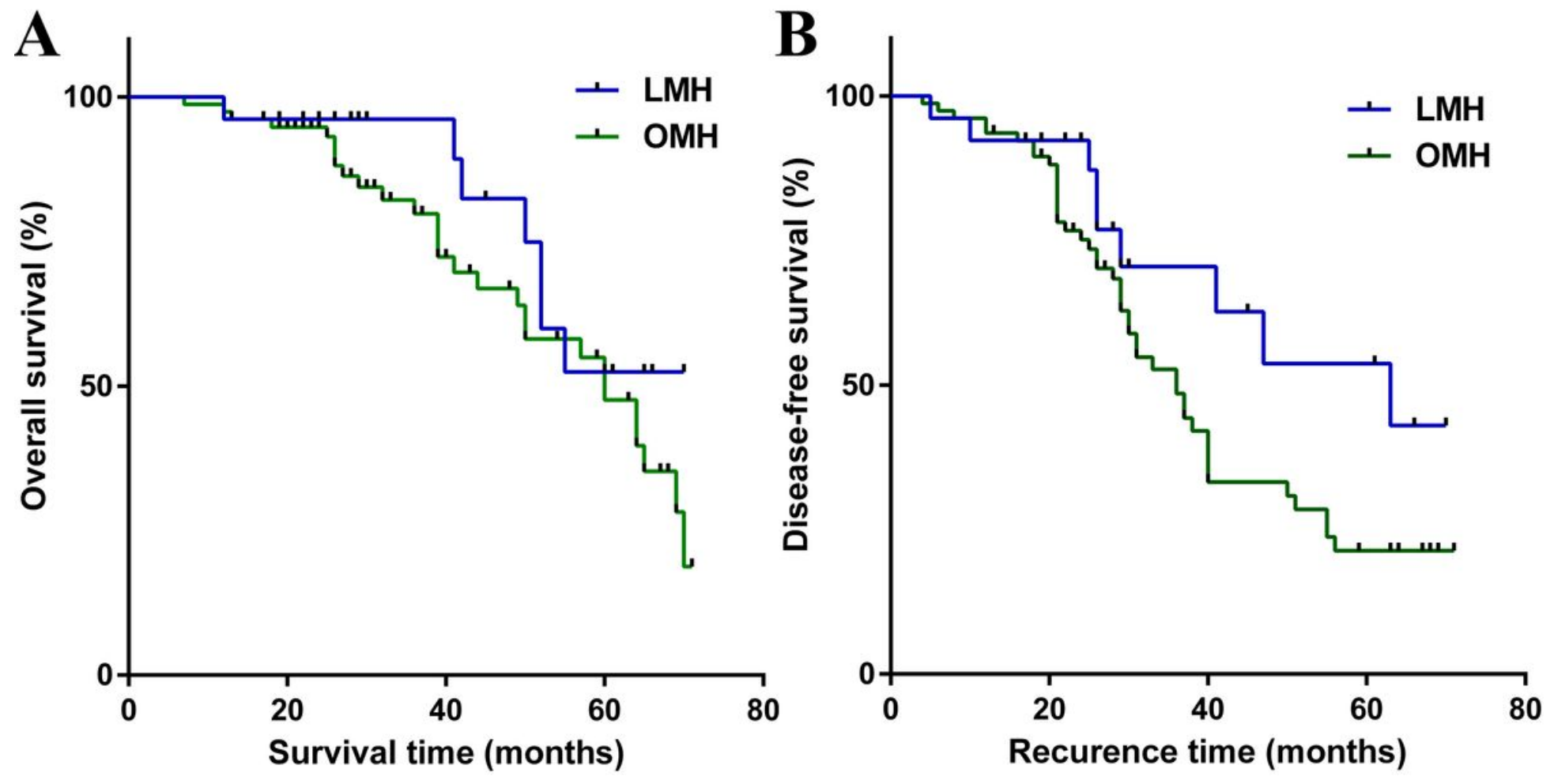

Figure 2

Weighted Kaplan-Meier plot for DFS and OS for LMH versus OMH. (A) Median DFS of LMH and OMH groups is 63.0 and 36.0 months ( $P=0.079$ ). (B) Median OS of LMH and OMH groups was 60.0 and 60.0 months $(P=0.172)$. 